\title{
TECHNOLOGY- AND HUMAN-INTENSIVENESS IN ROOM RATE-SETTING: A STUDY OF FOUR STYLES AMONG ASIA-PACIFIC HOTELS
}

\author{
Lewis K. S. Lim \\ Nanyang Business School \\ Nanyang Technological University \\ Singapore \\ Sheryl E. Kimes \\ School of Hotel Administration \\ Cornell University \\ Ithaca, NY, USA
}

Room rate-setting is a complex and challenging task that carries many financial and non-financial consequences for hotels. The extent to which a hotel emphasizes technology and/or human processes defines its rate-setting style. A survey of 170 hotels in the Asia-Pacific region reveals that hotels generally practice four major rate-setting styles. The style varies not only across hotels but also among hotels within the same chain. Importantly, hotels practicing the high technology-intensive/high human-intensive style are likely to produce better financial performance than other hotels. Hotels can promote both technologyand human-intensiveness by developing certain organizational traits and cultures. This research contributes toward a deeper understanding of hotel rate-setting by shedding light on the consequences and motivating factors of different rate-setting styles.

KEYWORDS: revenue management; pricing; room rates; technology use; human processes; hotel performance 


\section{INTRODUCTION}

Setting room rates is one of the most crucial functions for any hotel (Cross et al , 2009; Kimes, 2011). The rates charged by a hotel directly affect its competitive position, occupancy and revenues on a daily basis (Hanks et al , 1992; Steed and Gu 2005). Ultimately, the room rate levels affect a hotel's overall financial performance (Enz et al , 2009; Anderson and Xie, 2010). At a subtler level, rate policies also influence the hotel's brand image and customer's perceptions of fairness (Prasad and Dev, 2000; Choi and Mattila, 2004; Taylor and Kimes, 2011). Because of the many tangible and intangible consequences involved, hotel managers view rate-setting as a complex and challenging task (Quain et al , 1999).

How do hotel managers go about setting room rates? Recent advances in hospitality research offer hotel managers a myriad of data-driven, technology-enabled tools, collectively known as revenue management (RM) systems, for determining room rates (Kimes, 1989; Weatherford et al, 2001). As a result of these advances, along with widespread commercialization by systems vendors and consultants, a common impression of rate-setting is that of a technology-intensive activity. ${ }^{1}$ Yet, anecdotal evidence suggests that many hotel managers, especially at the property level, are averse to relying on technology to set room rates (Kimes, 2003). Our personal interactions with corporate RM specialists at several hotel chains reveal that property general managers require a great deal of persuasion before adopting the chains' RM systems. It appears that, at many hotels, rate-setting remains a human-intensive activity that involves face-to-face meetings, exchange of opinions and verbal deliberations among the property management team members (typically comprising the general manager, revenue manager and director of sales). 
In practice, of course, hotels have access to both technological and human inputs for ratesetting. The emphasis on either type of inputs is a question of degree. Accordingly, one can classify hotel rate-setting behavior along the two dimensions of technology-intensiveness (that is, how intensively a hotel utilizes scientific/technical resources such as quantitative models, computational tools and IT systems to set rates) and human-intensiveness (that is, how intensively a hotel relies on decision makers' mutual consultation and personal participation in discussions about viable rates to charge). ${ }^{2}$ The two dimensions are independent of each other. Just as some hotels can be highly intensive on one dimension and not intensive on the other, some hotels can also be highly intensive on both dimensions or not intensive on either dimension. Both technology- and human-intensiveness are concepts that are deeply rooted in the pricing literature as explained below.

Whether a hotel chooses to be technology-intensive or human-intensive (or both) is not a trivial concern and can have an important bearing on how the entire revenue planning process operates. The critical question is: Does either technology-intensiveness or human-intensiveness produce room rates that result in better occupancy, margins and/or RevPAR performance for hotels? Despite voluminous research on hotel pricing, few studies have investigated the financial consequences of technology- versus human-intensiveness. We therefore do not have a definitive knowledge of whether technology-intensiveness or human-intensiveness produces better financial performance. We also do not know whether customers are more satisfied, and whether the hotel managers themselves feel they are in better control of the rate decisions when a hotel adopts a particular rate-setting approach. Furthermore, research remains uninformed as to what factors motivate a hotel to become more technology-intensive or human-intensive in the first place. As a result, hotel managers receive little guidance as to how they can influence their 
hotels' rate-setting approach toward either greater technology-intensiveness or greater humanintensiveness.

The purpose of this study is threefold. First, we set out to empirically document the styles of hotel rate-setting in terms of the degrees of technology- and human-intensiveness. The term 'rate-setting' in this article encompasses both the initial determination of room rate levels and the coordination of rates across room categories to maintain integrity and logic, as well as the management of rate-change increments over time. Second, we seek to empirically assess the consequences of technology- and human-intensiveness. Our results show an interaction effect of the two dimensions on financial performance (measured in terms of self-reported revenue growth, operating margins and RevPAR relative to competitors), implying that the high technology-intensive/high human-intensive style is most likely to generate superior financial performance. Finally, we explore several hotel characteristics that are associated with technology-intensiveness and human-intensiveness. Our analysis suggests that a particular hotel trait - the tendency to seek and exploit technological advancements - motivates greater technology-intensiveness, whereas a particular hotel culture - one that stresses flexibility and spontaneity and that tolerates ambiguity and experimentation - promotes greater humanintensiveness.

This research contributes toward a deeper understanding of hotel rate-setting. By documenting different styles of hotel rate-setting, this study provides empirical evidence that hotels (even within the same chain) vary considerably in the extent to which they utilize technological and human resources for setting room rates. By assessing the consequences of technology- and human-intensiveness, this study sheds light on whether adopting a particular 
style is beneficial to hotels. Finally, by exploring the hotel traits and culture associated with technology- and human-intensiveness, this research reveals the motivating factors that hotels can influence in order to promote a particular rate-setting style.

\section{CONCEPTUAL FOUNDATIONS OF THE FOUR STYLES OF RATE-SETTING}

\section{Technology-intensiveness}

The notion that a firm's pricing approach can be described in terms of its technologyintensiveness is not new. Early scholarly pricing works dating back to the 1950s have long alluded to a technology-driven pricing discipline. Scholars such as Dean (1950), Oxenfeldt (1960) and Sampson (1964) touted the use of systematic data-driven approaches to solving various pricing problems. The emphasis on technology became evident with Good's (1968) work on using computers for pricing. Oxenfeldt (1973) subsequently highlighted the promising deployment of technology in pricing:

The most promising methods [in pricing] are: use of the computer; simulation as a method for anticipating the effect of price changes on sales and for testing complex strategies; research techniques for obtaining more reliable information about prospective customer responses to price change ....

Oxenfeldt (1973, p. 49)

Also contributing to the technological undertone are the three decades of work in optimal price modeling (for a review, see Rao, 2009), which are grounded in the techniques of operations 
research and management science (OR/MS) and which focus on producing mathematically tractable solutions to pricing problems (for example, Dolan and Jeuland, 1981; Thompson and Teng, 1984). Much of this research demonstrates that prices can be optimized if given the right parameters and objective functions.

In the professional pricing literature, authors also have explicitly argued for the need to invest in pricing technology. Notably, Monroe (2003) discusses the importance of having appropriate information systems and applications to support profitable price decision making. Marn et al (2004) proclaim that '[pricing technology] is an essential component of building the ongoing pricing capabilities of a company ... we have never seen a company make significant progress on the pricing front without upgrading its information systems' (p. 161), before subsequently devoting an entire chapter on implementing technology-driven pricing systems. Dutta et al (2002) illustrate the lost opportunities at companies that failed to exploit computing resources for improving the pricing process. Recent developments of pricing execution frameworks, such as Six Sigma Pricing (Sodhi and Sodhi, 2011), also imply the heavy use of information technology and systems to enforce pricing discipline.

\section{Human-intensiveness}

The idea that pricing approaches have varying degrees of human-intensiveness also has roots in traditional literature. Specifically, there exists a school of thought that contends that pricing problems are inherently complex and are highly susceptible to conflicts between departments within the same organization. Pricing issues therefore cannot be fully addressed through technology-based or data-driven methods. The genesis of such thinking can be traced to behavioral and evolutionary theories of the firm (Cyert and March, 1963; Nelson and Winter, 
1982) that stress the value of tacit know-how and learning routines in the creation of firm competitive advantage. Indeed, the involvement of various functional areas can embed conflict into the pricing process, as functional areas often compete with one another for resources and in the pursuit of divergent goals and strategic priorities (for example, Houston et al , 2001). Consequently, pricing decisions are subject to various conflicting intra-organizational concerns, generating a need for interpersonal relations and close intra-organizational coordination (Cyert and March, 1963; Majumdar, 1998). Accordingly, managers can learn to price effectively only when they personally involve themselves in the day-to-day pricing deliberations with colleagues and use internal coordination routines to resolve any interdepartmental conflicts (Dutta et al, 2003).

Empirical studies that support the human-intensive school of thought in pricing include Kaplan et al 's (1958) case studies. Having conducted extensive field work over a period of 10 years, these authors observed that corporations often had tacit goals that guided their pricing decisions, and their pricing activities often involved the simultaneous balancing of interests and avoidance of conflicts with implicit discernable pricing patterns or norms. The process-tracing studies by Farley et al (1980) and Morgenroth (1964) also documented the complex decision sequences that involve close coordination across departments in price setting and price adjustment decisions. Those findings suggest that effective pricing decisions are inherently adaptive and geared toward conflict resolution. Finally, Dutta et al (2003), who conducted an indepth study of pricing processes at a large industrial firm, observed passionate disputes among members of the pricing team. They found that, even with a sophisticated pricing software system, the firm could not immediately overcome the immense complexities of pricing. From these observations, they conclude that the key to building pricing capabilities is through a set of 
human-intensive routines and coordination mechanisms for price intelligence gathering, and exchanging different internal opinions.

\section{Integrating technology- and human-intensiveness}

Conceptually, technology- and human-intensiveness in pricing (or rate-setting in the hotel context) are distinct constructs. Since most hotels are likely to have access to (and can make a choice to use) different amounts of technological and human resources to carry out the ratesetting process, it is theoretically possible for a hotel to exhibit a high or low degree on each continuum. Recognizing that hotels can exhibit varying degrees of technology-intensiveness and human-intensiveness in their rate-setting process, we use a two-by-two matrix to describe hotel rate-setting styles. Figure 1, shows four possibilities.

First, some hotels are highly technology-intensive in their rate-setting process but are less open to human intervention (Style A). These hotels place heavy reliance on using of state-of-theart data-driven/IT tools to compute optimal rates across all customer categories or booking situations. Managers rarely override the computed optimal rates. Second, some hotels are highly human-intensive in their rate-setting but are less receptive to technological tools (Style B). These hotels arrive at room rates through consensus among key decision makers, who draw on their experience and market knowledge to gauge what rates the market can bear. Rather than depend on IT tools, the decision makers meet frequently as a committee to actively discuss and exchange insights about potential customer and competitor reactions to rate changes, as well as to coordinate rate differences across room categories. Third, some hotels are both highly technology-intensive and highly human-intensive (Style C). These hotels not only deploy sophisticated technology and RM models in their rate-setting process, but also insist on having 
human intervention in rate decisions. Typically, they utilize the IT systems to generate rate recommendations, but even as they fully comprehend the scientific basis of the computations, they will use their judgment to override the recommendations if they do not think the rates are workable. Finally, some hotels are neither technology-intensive nor human-intensive in their rate-setting process (Style D). These are hotels that do not have any formal system for ratesetting. Their managers set room rates neither by applying any specialized analytical techniques nor by actively debating pricing considerations and implications in a committee. Instead, room rates are mostly determined by simple rules of thumb or inherited conventions.

Given at least four possible rate-setting styles, one would question which style is likely to produce better hotel performance. By theoretical reasoning, we postulate that Style C, which combines the science of data analytics and the art of human judgment, will result in the most sensible room rates, which in turn maximize financial performance for hotels. Specifically, hotels can complement the computational precision and analytical prowess of technological ratesetting tools with the deep managerial insights and collective wisdom of human decision makers to arrive at performance-maximizing room rates. From an economics perspective, two resources are complementary when the marginal benefit of adding one resource increases as more of the other resource is added (Milgrom and Roberts, 1990; Siggelkow, 2002). Technology and human inputs are complementary for the following reasons. First, human insights can complement the technological focus on pricing tools, techniques and computerized applications to further enhance the commercial soundness of pricing decisions. By mutually sharing insights within rate-setting teams, managers are likely to better understand the subtleties of market requirements and gain greater insights into the causes of price movements, the pricing tactics of competitors and the psychological impact of price changes on customers (Dickson, 1992; Day, 1994). These 
insights can be used to substantiate or cross-validate the recommendations generated by datadriven tools. Second, technology-intensiveness can help focus the internal communication and tacit routines in human-intensive processes on financial accountability, thus enhancing the financial effectiveness of pricing decisions. Specifically, data from RM software can help reduce any unnecessary experimentation involved in finding appropriate prices to charge. In addition, the use of a systematic rate-setting framework should facilitate discussions of pricing issues among department managers, supplying a common technical vocabulary of pricing terms, and providing a basis for quantifying pricing impacts, thereby adding precision to the financial assessments made by managers.

Admittedly, the presence of technological aids will not completely eliminate groupthink tendencies that may occur in any committee-based human decision making process. However, the emphasis on evidence-based data analysis helps foster a disciplined objective decision making culture that reduces the negative impacts of groupthink. As a case in point, the judgmental forecasting literature (see Lawrence et al , 2006; Wright and Rowe, 2011) provides general support that forecasting accuracy can be enhanced when group-based human judgments are incorporated into model-driven forecasting processes. Human judgments are, of course, susceptible to biases, but the committee-based nature of the judgmental forecasting process enables mutual error checking and serves to increase task motivation and satisfaction, which in turn can improve the quality of forecasts (Kerr and Tindale, 2011).

To test our predictions about the efficacy of a high technology-intensive/high humanintensive rate-setting style, we carried out a survey in the Asia-Pacific region. The next section describes the survey design and procedures. 


\section{AN ASIA-PACIFIC HOTEL SURVEY}

\section{Sample and procedures}

With the assistance of the corporate offices of four major hotel chains, ${ }^{3}$ we conducted a survey of general managers of 332 hotels in the Asia-Pacific region. In contrast to hotels in North America and Europe where rate-setting practices are better developed (and arguably more technological across the board), Asia-Pacific hotels represented an interesting sample to study because their rate-setting practices were still evolving and therefore more varied. The hotels chosen for this study were also diverse in terms of their sizes, location types and segments served (see Table 1). The online survey required about 20 min to complete. At all four chains, the corporate office helped distribute our survey request to the general managers and sent reminders to late respondents where necessary. ${ }^{4}$ Our response rate of 54 per cent resulted in 170 cases usable for analysis. ${ }^{5}$

\section{Measures}

The survey included questionnaire scales designed to measure organizational tendencies and behaviors. Several scales were newly developed while the rest were well established in previous research (Table 2 ). ${ }^{6}$ The scales typically consisted of statements to which the respondents had to indicate their extent of agreement (from 1 for 'Strongly Disagree' to 7 for 'Strongly Agree'). At least three statements were used to measure each aspect of the hotel tendencies or behaviors, so as to enhance measurement reliability. The first set of scales probed the nature of rate-setting at the respondent's hotel. The remaining scales measured the hotel's organizational characteristics, operating environment and performance levels in terms of 
financial performance, customer satisfaction (with the hotel's rate policies) and managerial satisfaction (with the rate-setting process). Financial performance, in particular, was measured using three items asking respondents to indicate how much faster/higher or slower/lower their hotels' revenue growth, operating margins and RevPAR were (in percentage terms) relative to major competitors in the past 12 months. ${ }^{7}$ All scales exhibited a Cronbach's $\alpha$ of greater than 0.70, indicating that the scale items were internally consistent (Nunnally, 1978) and scale ratings could be averaged within their respective sets to form a summary score.

\section{Analysis and results}

Evidence of four rate-setting styles

Using the summary scores of technology-intensiveness and human-intensiveness, we performed cluster analysis to identify groups of hotels that exhibited similar rate-setting behavior. We used cluster analysis as the grouping technique because it enabled us to objectively delineate groups based on statistical measures of multidimensional distance among cases (Ketchen and Shook, 1996), as opposed to arbitrarily dividing the sample based on, say, high versus low absolute summary scores (cutoff at 4 or at the median) on technology- and humanintensiveness. We adopted a two-step clustering procedure recommended by Punj and Stewart (1983) to divide the 170 hotels into distinct groups. In the first step, we performed hierarchical clustering via the Ward's method to obtain a tree diagram (called a dendrogram; see Figure) that sorted the 170 hotels into 'branches' based on how close their technology- and humanintensiveness scores were. The dendrogram showed four main branches, indicating that four was the appropriate number of clusters to divide the sample into. ${ }^{8}$ In the second step, we used the mean scores from the four hierarchical branches as inputs to a $K$-means sorting sequence to 
regroup the hotels into exactly four clusters. The purpose of the second step was to fine-tune the grouping while keeping the number of clusters to four. The use of a two-step clustering procedure provided additional statistical rigor by compensating for the limitations of using either hierarchical or $K$-means clustering only, thereby increasing the validity of the cluster solution (Milligan 1980; Ketchen and Shook, 1996).

Figure 3, shows the result of the cluster analysis. From the overall dispersion of points, it is evident that the 170 hotels displayed varying degrees of technology- and human-intensiveness in their rate-setting approaches. Furthermore, the four identified clusters corresponded to the four styles of hotel rate-setting described earlier. Specifically, Style A and C hotels had higher technology-intensiveness scores than Style B and D hotels, and Style B and C hotels had higher human-intensiveness scores than Style A and D hotels. This was confirmed by an ANOVA contrast test, which indicated that the combined technology-intensiveness mean score of Style A and $\mathrm{C}$ hotels was significantly greater than the combined technology-intensiveness mean score of Style B and D hotels, whereas the combined human-intensiveness mean score of Style B and C hotels was significantly greater than the combined human-intensiveness mean score of Style A and D hotels. Therefore, the data support the notion of hotel rate-setting styles conceived in terms of technology- and human-intensiveness.

Interestingly, rate-setting style varied not only across hotels, but also within individual chains (Table 3 ). With the exception of Chain 3, which had hotels exhibiting three of the four styles, all chains had hotels that spanned all four styles. Furthermore, within each chain, the distribution of hotels across the different styles was fairly spread out (Figure 4). It appears that chain management has little effect on individual hotels' rate-setting styles. 
Performance differences among the styles

To determine whether the rate-setting style carried any implications for hotel performance, we first compared the reported financial performance scores across the four styles (Table 4 ). Style C hotels (highly technology-intensive and highly human-intensive) displayed the highest financial performance, whereas the performance levels of the other three styles were fairly similar. An ANOVA contrast test confirmed that the mean financial performance score for Style C hotels was significantly greater than the combined financial performance mean score of Style A, B and D hotels (and post hoc multiple comparison tests revealed no significant differences in the performance levels of Style A, B and D). This suggests that relying on e ither technological or human processes alone does not translate into better financial performance; it is only when a hotel combines technological and human processes in rate-setting that its financial performance can improve.

To more clearly see the performance impacts of the styles, we divided the sample into four quartiles according to the hotels' financial performance scores and examined the distribution of rate-setting styles within each quartile (see graph in Figure 5). The graph shows that Style C hotels were found more frequently in the top two quartiles than in the bottom two quartiles. In the topmost quartile, while substantial proportions of Style A and B hotels (31.0 per cent and 21.4 per cent, respectively) were present, there were nearly twice as many Style C hotels than there were in the bottommost quartile (38.1 per cent versus 20.9 per cent). And, in the topmost quartile, the proportion of Style D hotels is relatively small (9.5 per cent).

To more rigorously test the above result, we ran a multiple regression with financial performance as the dependent variable and several factors as independent variables. We 
incorporated the number of rooms (as an indicator of hotel size) and a 'financial slack' score (measuring the amount of discretionary financial resources available) into the regression model to isolate these two effects. In addition, a hotel's operating environment could have a bearing on its financial performance (Dess and Beard, 1984), so we added variables representing three aspects of the hotel environment. ${ }^{9}$ Regardless of the direction of effects, the main reason for including these variables was to make sure that the performance differences among the hotels could be attributed solely to the rate-setting style and not to the different local environment that each hotel faced. To formally test the effect of hotel rate-setting style, we used three main variables: technology-intensiveness, human-intensiveness, and a multiplicative term representing the interaction between technology- and human-intensiveness. ${ }^{10}$

Indeed, the regression results show that, after isolating the effects of hotel size, financial slack and environment, the interaction between technology- and human-intensiveness had a significant positive effect on financial performance (Table 5 ). The results also show that humanintensiveness by itself had a significant positive effect on financial performance. At average levels of technology-intensiveness (that is, under 'normal' circumstances), raising the humanintensiveness of rate-setting will enhance the hotel's financial performance.

Apart from financial performance, hotel rate-setting style can possibly affect customer satisfaction levels. It is possible that, unlike purely technology-driven rate-setting approaches that aim to optimize financial outcomes with little consideration for customers' psychological responses, human intervention in the rate-setting process may promote greater care for customer sentiments toward rate changes. To measure this, we ran a regression analysis to test the effects of technology- and human-intensiveness on customer satisfaction. ${ }^{11}$ The results (Table 5 ) show 
no evidence of either technology- or human-intensiveness helping to raise reported customer satisfaction levels. A comparison of the average customer satisfaction level by rate-setting style (Table 4 ) did indicate a slightly higher customer satisfaction in Style B and C (which are more human-intensive in nature) than in Style A and D, but the difference was not statistically significant. Further research, perhaps with actual rather than perceived customer satisfaction ratings, is needed to confirm the presence of any customer satisfaction effects.

\section{Other organizational consequences}

Apart from financial performance and customer satisfaction, hotel rate-setting style can also carry other consequences for the hotel organization. One consequence, which is not typically classified as a 'performance' outcome but no less important from an overall organizational effectiveness perspective, is decision makers' sentiment toward the rate-setting process (referred to here as 'managerial satisfaction' for simplicity). In order to operate an effective decision making process that consistently generates sensible room rates, key decision makers (including the general manager, the revenue manager and the director of sales) need to feel they are in control of the situation and be confident that they are managing the process well. To investigate the effect of rate-setting style on managerial satisfaction, we again ran a regression analysis. ${ }^{12}$ In this regression, the dependent variable was a managerial satisfaction score derived from five survey items measuring the respondents' pleasure/displeasure with the rate-setting process. The results (see Table 5 ) show that both technology-intensiveness and human-intensiveness helped raise managerial satisfaction. A comparison of the average managerial satisfaction level by rate-setting style (see Table 4 ) points to these effects. Specifically, both Style A and B exhibited higher managerial satisfaction levels than Style D, 
implying that a greater utilization of either technological or human resources led decision makers to feel in better control of the rate-setting task. As the regression results did not indicate any significant interaction effect, the managerial satisfaction level of Style C was simply the outcome of adding technology-intensiveness to human-intensiveness, with no synergy achieved.

Hotel characteristics associated with technology-and human-intensiveness

Having found several benefits of technology- and human-intensiveness (either individually or in combination), we studied which hotel traits or culture give rise to the tendency to rely on either technological or human resources for rate-setting. If management knows which trait or culture is conducive to grooming technology- or human-intensiveness, than management can promote that trait or culture. For a preliminary investigation, we explored four plausible traits and cultures:

Trait 1: Technological opportunism . As a general organizational trait, technological opportunity is the tendency of an organization to actively scan the environment for technological developments and to adopt new and innovative technologies for management purposes (Srinivasan et al , 2002). Technologically opportunistic companies are highly receptive to employing sophisticated science/engineering tools (including IT tools) for a variety of applications, provided such technologies are detectable within the environment. As technologyenabled rate-setting tools are widely promoted within the hotel industry, we deduced that technologically opportunistic hotels are likely to adopt these tools and be highly technologyintensive in their rate-setting approach. 
Trait 2: Intelligence dissemination . Intelligence dissemination is the tendency for organizational members to share and exchange market information across departments or functions (Kohli and Jaworski, 1990). Companies displaying the intelligence dissemination trait believe that active sharing of market information, not only through formal reports but also through informal interaction among managers across departments, helps improve the quality of decisions. Because these companies tend to have close communication ties among key decision makers, and these ties in turn promote the mutual consultation and coordination of business decisions (a characteristic of human-intensiveness), it is reasonable to expect that hotels with high degrees of intelligence dissemination are also highly human-intensive in their rate-setting approach.

Culture 1: Hierarchy culture. A hierarchy culture is one that emphasizes rules, formalities and procedures aimed at minimizing disruptions in operations (Deshpande et al , 1993). Companies that possess a hierarchical culture tend to be very structured in the way they make decisions and prefer to rely on systematic methods with clear documentation for solving problems. Because these companies are likely to embrace data-driven tools and techniques, which provide a high degree of precision and objectivity along with recordable data trails to decisions made (a benefit sought in technology-intensiveness), it is reasonable to believe that hotels possessing the hierarchy culture are also technology-intensive in rate-setting.

Culture 2: Adhocracy culture. In contrast to hierarchy culture that values formality, an adhocracy culture is one that emphasizes flexibility and spontaneity (Deshpande et al , 1993). Companies possessing the adhocracy culture tend to encourage experimentation and risk taking, and are more tolerant of ambiguous outcomes. Because these companies recognize that not all 
decision inputs can be stated in structured/numerical terms or be analyzed by formulas and models, decision making often occur through verbal deliberations among managers based on qualitative, situation-specific insights gained from personal experience. As this closely corresponds to the human-intensive approach to rate-setting, hotels possessing the adhocracy culture are likely to exhibit strong human-intensiveness.

To investigate the above possibilities, we first computed scores of technological opportunism, intelligence dissemination, hierarchy culture and adhocracy culture for each hotel based on survey items designed to measure these traits and cultural characteristics. We then compared the average score for each trait/culture by rate-setting style (Table 4 ). Hotels exhibiting Style A and C (with higher technology-intensiveness scores) were more technologically opportunistic than hotels exhibiting Style B and D (with lower technologyintensiveness scores). Hotels exhibiting Style B and C (with higher human-intensiveness scores) practiced more intelligence dissemination than hotels exhibiting Style A and D (with lower human-intensiveness scores). Hotels exhibiting Style A and C (with higher technologyintensiveness scores) were more hierarchical in culture than hotels exhibiting Style B and D (with lower technology-intensiveness scores). Finally, hotels exhibiting Style B and C (with higher human-intensiveness scores) had higher adhocracy culture scores than hotels exhibiting Style A and D (with lower human-intensiveness scores). ANOVA contrast tests confirmed that these intergroup differences were significant.

To more rigorously test the preceding results, we ran two sets of multiple regression with technology- and human-intensiveness serving as the respective dependent variables and the four trait and culture scores serving as independent variables. We also included hotel size (measured 
by the number of rooms), financial slack (measured by three survey items), the number of customer segments served (as a measure of rate-setting task complexity), the length of the general manager's industry experience (as an indicator of traditional versus modern management thinking) and two dummy variables signifying the three location types (urban, suburban and resort) (Table 6 ). The purpose for doing so was to isolate their effects on baseline technologyand human-intensiveness levels. ${ }^{13}$ Despite the more stringent regression test with a greater number of control factors, the effect of technological opportunism on technology-intensiveness and the effect of adhocracy culture on human-intensiveness remained significant. In other words, a general technological opportunism trait helped stimulate technology-intensiveness, while an adhocracy culture helped promote human-intensiveness in rate-setting. The effects of intelligence dissemination and hierarchy culture were insignificant.

\section{DISCUSSION}

This research has aimed to provide a deeper understanding of hotel rate-setting and distinguishable styles. We found that hotels (both within and across chains) practice very different rate-setting styles. Some hotels primarily use technological means such as quantitative models, computational tools and IT systems to set room rates, while some hotels work out room rates primarily through human-intensive processes such as face-to-face meetings, exchange of insights and verbal deliberations among key decision makers. Yet some other hotels are able to integrate both technological and human processes in their rate-setting practices. Inevitably, a number of hotels utilize neither technology nor human inputs, relying instead on simple rules of thumb or inherited conventions to determine room rates. 
More importantly, in line with our prior theoretical expectation, we found that hotels that manage to combine the computational precision and analytical prowess of technological ratesetting tools with the deep managerial insights and collective wisdom of human decision makers tend to be the best performing. Among the 170 hotels studied, this group of hotels (Style C hotels) reported superior financial performance levels to other hotels, presumably because their rate-setting process had enabled them to set very sensible room rates that enhanced their revenue growth, operating margins and/or RevPAR.

Hotels should therefore consider increasing both the technology-intensiveness and the human-intensiveness of their rate-setting process. The ideal situation is of course to achieve concurrently high degrees of technology-intensiveness and high degrees of human-intensiveness. But even for hotels with average degrees of technology-intensiveness, simply increasing the degree of human-intensiveness can raise financial performance levels (as the significant regression coefficient of human-intensiveness suggests). At any rate, increasing either the technology-intensiveness or the human-intensiveness of rate-setting can enhance hotel managers' satisfaction with the rate-setting process, allowing them to feel more at ease with the challenging rate-setting task and be more confident that they are doing a good job.

To promote both technology-intensiveness and human-intensiveness, hotels should realize that the underlying drivers of each behavior are different. As the results of this study suggest, technology-intensiveness is driven by the hotel's general tendency to seek and adopt scientific innovations - an organizational trait called technological opportunism. By encouraging technological opportunism, hotels can indirectly cultivate technology-intensiveness in the area of rate-setting. In contrast, human-intensiveness is driven by a culture that tolerates spontaneity, 
flexibility and ambiguity - that is, an adhocracy culture. By not insisting that every decision needs to be backed by some structured/quantifiable formula, and by recognizing that qualitative, experience-based opinions represent equally valuable decision inputs, hotels can foster an adhocracy culture and indirectly promote human-intensiveness in rate-setting. As technological opportunism and adhocracy culture are not fundamentally opposed, there is no reason to believe that a hotel cannot promote both technology-intensiveness and human-intensiveness at the same time. Importantly, hotels should realize that organizational traits and cultural characteristics occur at the property level. (In the sample studied, hotels with same chain display varying degrees of technological opportunism and adhocracy.) While chain management can provide some overarching guidance and incentives to adopt certain norms, much will depend on the property-level management (in particular the general manager) to champion desirable organizational traits or cultural characteristics. The primary target of education about the usefulness of technological opportunism and adhocracy, and ultimately the benefits of technology-and human-intensiveness, should therefore be the property-level management.

\section{Limitations and future research directions}

As a pioneering investigation into hotel rate-setting styles, this study has taken a broad approach to classifying rate-setting behaviors and assessing performance consequences. To maintain conceptual elegance, we focused on two broad dimensions of rate-setting behavior, namely, technology-intensiveness and human-intensiveness. Performance in this study is also a broad financial variable encompassing revenue growth, operating margin and RevPAR. Indeed, our data support the existence of four different rate-setting styles as defined by the two dimensions. And the style holds implications for financial performance levels. However, it is 
possible that, within each broad style, there are finer distinctions in hotel rate-setting behavior, or that there are more complex multidimensional ways to delineate rate-setting styles, and this study has not pursued these finer details. This study also has not examined the intermediate chain of effects linking rate-setting style and financial performance. Therefore, the explanation for why the high technology-intensive/high human-intensive style produces the best performance level remains theoretical at best. In view of these limitations, future research could take a finer-grained approach to studying rate-setting styles, investigating perhaps certain sub-components of technology- and human-intensiveness or other dimensions, as well as how precisely a particular rate-setting style affect managers' motivation, decision making dynamics and quality of rate decisions which in turn lead to hotel financial performance.

In terms of methodology, this study has also relied only on survey data obtained from single informants at each hotel. While the survey allowed us to measure aspects of hotel practices or management tendencies that are otherwise not observable (such as the management's beliefs about the indispensability of technological tools for rate-setting and the extent to which they are pleased with the rate-setting process), a number of variables (particularly financial performance and customer satisfaction levels) could be better corroborated using objective data. Also, multiple sources of data (including data obtained at different time intervals) could be utilized to cross-validate the measurements. To that end, future research could involve a greater variety of measurement methods to tap hotel rate-setting tendencies and to record outcomes. Besides undertaking a cross-sectional study to compare rate-setting styles and performance levels across hotels, researchers could also use an in-depth case study approach to investigate how rate-setting styles arise and evolve over time within individual hotels. Together, these efforts should generate richer data for a more enlightened understanding of the topic. 


\section{NOTES}

1. We use the term 'technology' in a broad sense. Technology refers not only to computer systems but also to scientific, research-driven applications. Being technological also connotes problem solving in a systematic, step-by-step fashion, with the aid of quantitative tools and techniques.

2. Note that human-intensiveness does not imply any lack of rigor in rate decisions. Compared to technology-intensiveness, the process can be equally, if not more, thorough and painstaking, except the rate-setting considerations tend to be more qualitative in nature. The process is also more dependent on specific individuals whose knowledge, unlike IT databases, is not necessarily documented in the hotel's institutional records.

3. The chain names are withheld by request of the corporate offices.

4. In cases where the general manager did not personally fill out the survey, another senior member of the hotel management team (typically the revenue manager) responded on the general manager's behalf.

5. For the purpose of this study, we treated the 170 cases as a single sample as subsequent tests ran with dummy variables to account for chain membership effects did not reveal any major differences in the results. 
6. In developing new scales, we followed research best practices prescribed by authorities such as Churchill (1979). The process included systematic item generation, selection, pretesting, validation and purification. Details of checks performed are available upon request.

7. Although we would have liked to have obtained data on actual financial performance, these data were not available, so the performance data were self-reported.

8. An examination of the agglomeration coefficient statistics also indicated that the incremental change in the coefficient would be much larger if a solution consisting of four clusters were to be merged into three clusters (that is, highly dissimilar clusters would be merged) than if five clusters were to be merged into four clusters, meaning that there would be greater dissimilarity among clusters with four clusters than with five clusters, and that having only three clusters would result in too much dissimilarity within clusters. A four-cluster solution was therefore optimal.

9. The first aspect was environmental munificence, which refers to how rich and bountiful the environment is in terms of available business opportunities that support growth. The second aspect was environmental dynamism, which refers to how rapidly business conditions change and how unpredictable future events are. The third aspect was environmental complexity, which refers to how diverse the market needs are and consequently how business must devise differentiated strategies and product offerings to cater to market needs. Generally, the more munificent the environment is, and the lower the environmental dynamism and complexity, the stronger the financial performance will be. 
10. In line with established statistical procedures (for example, Aiken and West, 1991), we centered the technology- and human-intensiveness scores at their respective means and multiplied the mean-centered scores together to derive the multiplicative term.

11. We used the same independent variables as in the financial performance regression model as, presumably, the same factors that affect financial performance can also affect customer satisfaction.

12. There was no reason to believe that factors such as hotel size, financial slack and environmental characteristics would make a difference to baseline managerial satisfaction levels. Therefore, we only included the two main variables and their interaction term in this regression model.

13. Preliminary examination of the data had suggested that (1) larger hotels tended to be both more technology-intensive and more human-intensive than smaller hotels, (2) hotels with greater financial slack tended to be more technology-intensive but no more human-intensive than hotels with lesser financial slack, (3) hotels serving large numbers of customer segments tended to be more human-intensive but no more technology-intensive than hotels serving small numbers of customer segments, and (4) general managers with the longest industry experience tended to be found in Style B hotels, which are highly human-intensive but not technology-intensive. 
Table 1. Sample characteristics.

\begin{tabular}{lll}
\hline Variable & Distribution of values & Graphical plot \\
\hline Size (number of rooms) & Range: 55-900 \\
Mean: 304 &
\end{tabular}

Location type

Urban $-69 \%$

Suburban $-15 \%$

Resort $-16 \%$

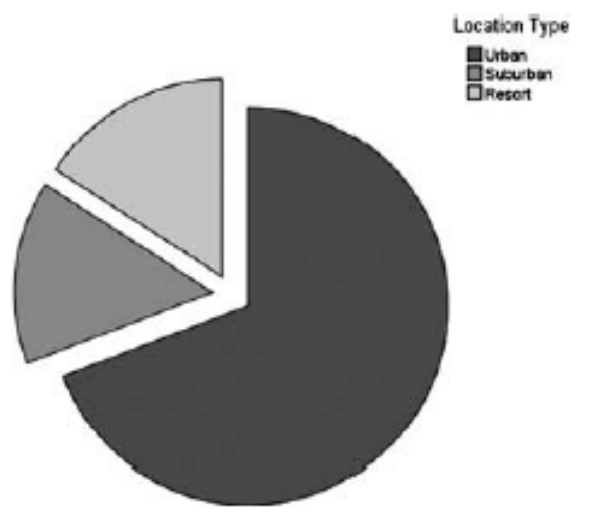

Number of customer segments served
1 to $3-6.5 \%$
4 to $6-31.2 \%$
7 to $9-23.5 \%$
10 to $12-14.7 \%$
13 to $15-8.2 \%$
16 to $18-5.3 \%$
19 to $21-5.3 \%$
22 or more $-5.3 \%$

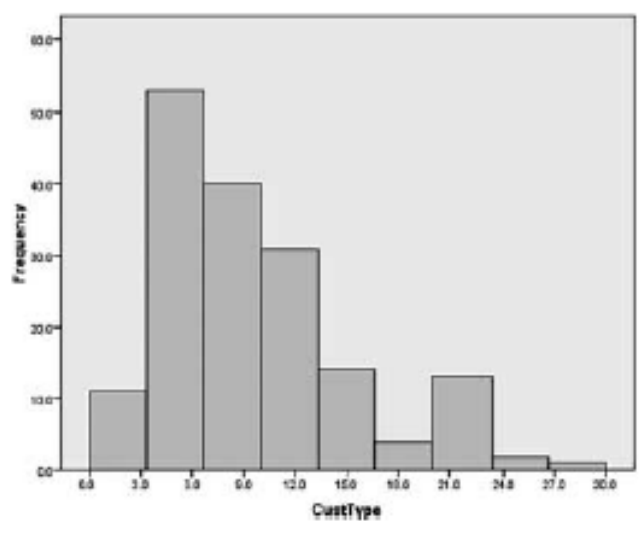


Table 2. Survey questionnaire scale items.

\begin{tabular}{|c|c|}
\hline Construct & Item \\
\hline $\begin{array}{l}\text { Technology-intensiveness } \\
\quad \text { in hotel rate-setting } \\
\quad \text { (new scale) } \\
\alpha=0.857\end{array}$ & $\begin{array}{l}\text { - We often use a dedicated software or decision support system to make rate-setting decisions. } \\
\text { - We often use computerized applications to set room rates. } \\
\text { - In our line of business, computing tools are indispensable for making rate-setting decisions. } \\
\text { - We invest a lot in information technology to support rate-setting. } \\
\text { - Rate-setting decisions at my hotel are driven a lot by the application of specialized tools and techniques. }\end{array}$ \\
\hline $\begin{array}{l}\text { Human-intensiveness in } \\
\quad \text { hotel rate-setting } \\
\quad \text { (new scale) } \\
\alpha=0.814\end{array}$ & $\begin{array}{l}\text { - We regularly share market rate information internally across different departments. } \\
\text { - We frequently hold pricing/rate-setting meetings among executives from different departments. } \\
\text { - We often utilize the combined insights of executives from different business functions when making rate-setting } \\
\text { decisions. } \\
\text { - We make it a point to incorporate inputs from executives from different departments whenever rate-setting decisions } \\
\text { need to be made. } \\
\text { - We always stress that our executives should acquire an intuitive sense of market room rates in order to do a better job in } \\
\text { rate-setting. }\end{array}$ \\
\hline $\begin{array}{l}\text { Financial performance } \\
\quad \text { (adapted from Vorhies } \\
\quad \text { and Morgan, 2005) } \\
\alpha=0.857\end{array}$ & $\begin{array}{l}\text { Thinking about your hotel unit's performance in the past } 12 \text { months ... } \\
\text { - Our revenue growth has been } \\
\text { - Our operating margins have been } \% \text { faster } / \text { slower }^{2} \text { relative to our major competitors. }_{\text {- }} \% \text { higher } / \text { lower }^{2} \text { relative to our major competitors. } \\
\text { - Our RevPAR has been }\end{array}$ \\
\hline $\begin{array}{l}\text { Customer satisfaction } \\
\quad \text { (adapted from Fornell } \\
\quad \text { et al, 1996) } \\
\alpha=0.820\end{array}$ & $\begin{array}{l}\text { Using a scale of } 1-10 \text {, where } 10 \text { is Outstanding and } 1 \text { is Unacceptable ... } \\
\text { - If our customers were to indicate how fairly they have been treated in the past } 12 \text { months, our average score would be } \\
\text { around } \\
\text { - If our customers were to indicate how satisfied they have been with our hotel rate policies in the past } 12 \text { months, our } \\
\text { average score would be around } \\
\text { - Given the rates our customers generally pay for our rooms and services, they would judge the quality of our rooms and } \\
\text { services to be around } \\
\text { - Given the quality our customers generally receive for rooms and services, they would judge the rates they pay for our } \\
\text { rooms and services to be around }\end{array}$ \\
\hline
\end{tabular}


Managerial satisfaction (new scale)

$\alpha=0.938$

Environmental munificence (adapted from Covin and Slevin, 1989; Miller, 1987) $\alpha=0.703$
Environmental dynamism (adapted from Miller and Friesen, 1982

- Those involved in rate-setting decisions in this hotel unit are very happy with how these decisions are generally made.

- Those involved in rate-setting decisions in this hotel unit are very happy with how rates are set.

- Most of our hotel unit's rate decision-makers find our rate-setting process to be an effective one.

- Most of our hotel unit's rate decision-makers always seem to be in good control of the situation when it comes to setting and managing room rates.

- In this hotel unit, the job of setting and managing room rates is a manageable one.

Doing business in this industry is very stressful and very hard to keep afloat

This industry environment is very risky; one false step could mean my hotel unit's undoing

This is an industry in which our hotel unit's initiatives count for very little against the tremendous competitive, technological or political forces

The market activities of our key competitors have become far more hostile

The market activities of our key competitors now affect our hotel unit in many more areas (eg, pricing, service, quality, etc.)

Our hotel unit must rarely change its marketing practices to keep up with the market and competitors

The speed at which products/services are getting obsolete in this industry is very slow

Actions of competitors are quite easy to predict

Demand and customer tastes are fairly easy to forecast

The operation/service technology is not subject to very much change and is well established $\begin{array}{lllllll}1 & 2 & 3 & 4 & 5 & 6 & 7\end{array}$

$\begin{array}{lllllll}1 & 2 & 3 & 4 & 5 & 6 & 7\end{array}$

$\begin{array}{lllllll}1 & 2 & 3 & 4 & 5 & 6 & 7\end{array}$

$\begin{array}{lllllll}1 & 2 & 3 & 4 & 5 & 6 & 7\end{array}$

$\begin{array}{llllll}2 & 3 & 4 & 5 & 6 & 7\end{array}$

$\begin{array}{lllllll}1 & 2 & 3 & 4 & 5 & 6 & 7\end{array}$

$\begin{array}{lllllll}1 & 2 & 3 & 4 & 5 & 6 & 7\end{array}$

$\begin{array}{lllllll}1 & 2 & 3 & 4 & 5 & 6 & 7\end{array}$

$\begin{array}{lllllll}1 & 2 & 3 & 4 & 5 & 6 & 7\end{array}$
This industry is rich in investment and marketing opportunities

This industry environment is very safe; there is little threat to the survival and well-being of our hotel unit

This is an industry in which our hotel unit can control and manipulate the environment to our own advantage

The market activities of our key competitors have become far less hostile

The market activities of our key competitors now affect our hotel unit in far fewer areas (eg, pricing, service, quality, etc.)

Our hotel unit must change its marketing practices extremely frequently to keep up with the market and competitors

The speed of product/service obsolescence in this industry is very high

Actions of competitors are highly unpredictable

Demand and customer tastes are highly unpredictable

The modes of operation/service change very often and in major ways 
Table 2. con't.

\begin{tabular}{ll}
\hline Construct & Item \\
\hline
\end{tabular}

\section{Environmental complexity (adapted from Miller and Friesen, 1982)} $\alpha=0.862$
Financial slack (adapted from Tan and Peng, 2003)

$\alpha=0.791$

\section{Technological opportunism} (adapted from

Srinivasan et al, 2002) $\alpha=0.858$
We serve a single, undifferentiated market with very similar customers

Our market consists of customers with relatively homogeneous requirements

Product forms and services are very similar in terms of required marketing strategy, types of customers, pricing, etc.

Our hotel unit does not need much diversity in our operating methods and marketing tactics to cater to our different customers

In this industry, there are not great differences in our customers' buying habits

\section{$\begin{array}{lllllllll}1 & 2 & 3 & 4 & 5 & 6 & 7 & \text { We serve a greatly diverse market with }\end{array}$ very different types of customers}

$\begin{array}{lllllll}1 & 2 & 3 & 4 & 5 & 6 & 7\end{array}$

$\begin{array}{lllllll}1 & 2 & 3 & 4 & 5 & 6 & 7\end{array}$

$\begin{array}{lllllll}1 & 2 & 3 & 4 & 5 & 6 & 7\end{array}$

$\begin{array}{lllllll}1 & 2 & 3 & 4 & 5 & 6 & 7\end{array}$
There is very great diversity in the requirements of customers in our market

Product forms and services are very dissimilar in terms of required marketing strategy, types of customers, pricing, etc.

Our hotel unit needs a lot of diversity in our operating methods and marketing tactics to cater to our different customers

In this industry, there are highly complicated differences in our customers' buying habits
- Over the past 3 years, our hotel unit's retained earnings have been more than sufficient for market expansion.

- Over the past 3 years, our hotel unit has been blessed with a pool of financial resources that can be used on a discretionary basis.

- Over the past 3 years, our hotel unit has been able to secure all necessary financing for our business needs.

- We are often one of the first in our industry to detect technological developments that may potentially affect our business.

- We actively seek intelligence on technological changes in the environment that are likely to affect our business.

- We periodically review the likely effect of changes in technology on our business.

- We generally respond very quickly to technological changes in the environment. 
Intelligence dissemination et al, 2000)

$\alpha=0.822$

Hierarchy culture (adapted from Deshpande et al, 1993)

$\alpha=0.711$

Adhocracy culture (adapted from Deshpande et al, 1993)

$\alpha=0.830$

Demographics/General information (adapted from Matsuno

- Marketing personnel in our hotel unit spend time discussing customers' future needs with other functional departments.

- Our hotel unit periodically circulates documents (eg, reports, newsletters) that provide information on our customers.

- We have cross-functional meetings very often to discuss market trends and developments (eg, customers, competition, suppliers).

- We regularly have interdepartmental meetings to update our knowledge of regulatory requirements.

- Technical people in this hotel unit spend a lot of time sharing information about technology for new products with other departments.

- Market information spreads quickly through all levels in this hotel unit.

- My hotel unit is a very formalized and structured place. Established procedures generally govern what people do.

- The head of my hotel unit is generally considered to be a coordinator, an organizer or an administrator.

- The glue that holds my hotel unit together are formal rules and policies. Maintaining a smooth-running institution is important here.

- My hotel unit emphasizes permanence and stability. Efficient, smooth operations are important.

- My hotel unit is a very dynamic and entrepreneurial place. People are willing to stick their necks out and take risks.

- The head of my hotel unit is generally considered an entrepreneur, an innovator or a risk taker.

- The glue that holds my hotel unit together is a commitment to innovation and development. There is an emphasis on being first.

- My hotel unit emphasizes growth and acquiring new resources. Readiness to meet new challenges is important.

- Approximately how many hotel rooms are there in your hotel unit? (measure for hotel size)

- Across how many different customer categories (eg, corporate, individual, tours) are your room rates maintained? (measure for number of customer segments served)

- How would you classify the location of your hotel unit? (Urban/Suburban/Resort)

- How many years of experience do you have with this industry? years

${ }^{2} \mathrm{Respondent}$ asked to indicate a percentage ranging from $50 \%$ slower/lower to $50 \%$ faster/higher.

Note: Unless otherwise specified, all items were measured on a 7 -point ( $1=$ strongly disagree; $7=$ strongly agree) scale. 
Table 3. Cross-tabulation of rate-setting style by chain

\begin{tabular}{lrrrrr}
\hline & \multicolumn{5}{c}{ Hotel rate-setting style } \\
\cline { 2 - 6 } & Style D & Style A & Style B & Style C & Total \\
\hline Chain & & & & & \\
1 & 2 & 1 & 3 & 1 & 7 \\
2 & 10 & 16 & 16 & 2 & 44 \\
3 & 0 & 5 & 7 & 11 & 23 \\
4 & 13 & 39 & 11 & 33 & 96 \\
Total & 25 & 61 & 37 & 47 & 170 \\
\hline
\end{tabular}

Numbers in cells are frequencies. 
Table 4. Comparison of performance and organizational characteristics by rate-setting style.

\begin{tabular}{|c|c|c|c|c|c|}
\hline \multirow[t]{2}{*}{ Variables } & \multicolumn{4}{|c|}{ Cluster means } & \multirow[t]{2}{*}{ Remarks } \\
\hline & Style $A$ & Style B & Style C & Style D & \\
\hline $\begin{array}{l}\text { Financial } \\
\text { performance }\end{array}$ & 8.62 & 9.59 & 13.89 & 7.87 & $\begin{array}{l}\text { ANOVA contrast test confirmed that the mean financial performance score for Style } \\
\text { C hotels was significantly greater than the combined financial performance mean } \\
\text { score of Style A, B and D hotels. }\end{array}$ \\
\hline $\begin{array}{l}\text { Customer } \\
\text { satisfaction }\end{array}$ & 7.31 & 7.54 & 7.56 & 7.25 & $\begin{array}{l}\text { Style B and C hotels (which practice more human-intensive rate-setting) reported } \\
\text { slightly higher customer satisfaction score than Style A and D hotels, but the } \\
\text { difference was not statistically significant }\end{array}$ \\
\hline $\begin{array}{l}\text { Managerial } \\
\text { satisfaction }\end{array}$ & 5.35 & 5.50 & 6.12 & 4.58 & $\begin{array}{l}\text { Style } C \text { hotels (which practice both technology-intensive and human-intensive rate- } \\
\text { setting) had higher managerial satisfaction level than hotels practicing any other } \\
\text { rate-setting style. }\end{array}$ \\
\hline $\begin{array}{l}\text { Technological } \\
\text { opportunism }\end{array}$ & 4.38 & 3.80 & 4.98 & 3.58 & $\begin{array}{l}\text { Style A and C hotels (with higher technology-intensiveness scores) were more } \\
\text { technologically opportunistic than hotels exhibiting Style B and D (with lower } \\
\text { technology-intensiveness scores) }\end{array}$ \\
\hline $\begin{array}{l}\text { Intelligence } \\
\text { dissemination }\end{array}$ & 4.56 & 4.66 & 5.37 & 4.13 & $\begin{array}{l}\text { Style B and C hotels (with higher human-intensiveness scores) practiced more } \\
\text { intelligence dissemination than hotels exhibiting Style A and D (with lower } \\
\text { human-intensiveness scores) }\end{array}$ \\
\hline $\begin{array}{l}\text { Hierarchy } \\
\text { culture }\end{array}$ & 4.68 & 4.42 & 4.91 & 4.51 & $\begin{array}{l}\text { Style A and C hotels (with higher technology-intensiveness scores) were more } \\
\text { hierarchical in culture than hotels exhibiting Style B and D (with lower } \\
\text { technology-intensiveness scores) }\end{array}$ \\
\hline $\begin{array}{l}\text { Adhocracy } \\
\text { culture }\end{array}$ & 4.91 & 5.01 & 5.59 & 4.20 & $\begin{array}{l}\text { Style B and C hotels (with higher human-intensiveness scores) had higher adhocracy } \\
\text { culture scores than hotels exhibiting Style A and D (with lower human- } \\
\text { intensiveness scores) }\end{array}$ \\
\hline
\end{tabular}


Table 5. Regression results: Effects of technology-intensiveness, human-intensiveness and their interaction on three outcomes.

\begin{tabular}{lccc}
\hline & \multicolumn{2}{c}{ Standardized beta estimates obtained for three dependent variables } \\
\cline { 2 - 4 } & $\begin{array}{c}\text { Financial } \\
\text { performance }\end{array}$ & $\begin{array}{c}\text { Customer } \\
\text { satisfaction }\end{array}$ & $\begin{array}{c}\text { Managerial } \\
\text { satisfaction }\end{array}$ \\
\hline Predictor variables: & & & \\
Technology-intensiveness & -0.03 & -0.04 & $0.19 \star \star$ \\
Human-intensiveness & $0.19 \star$ & 0.10 & $0.40 \star \star$ \\
Technology $\times$ Human-intensiveness & $0.15 \star$ & 0.06 & -0.01 \\
interaction & & & \\
& & & \\
Control variables: & 0.11 & -0.07 & n.a. \\
Environmental munificence & -0.05 & 0.02 & n.a. \\
Environmental dynamism & -0.07 & 0.15 & n.a. \\
Environmental complexity & -0.12 & 0.07 & n.a. \\
Hotel size (number of rooms) & $0.24 \star \star$ & $0.24 \star \star$ & \\
Financial slack & & & $18.419 \star \star$ \\
Model statistics: & $4.120 \star \star$ & $2.237 \star$ & 0.25 \\
F-value & 0.17 & 0.10 & \\
$R^{2}$ & & & \\
\hline
\end{tabular}

$\star P<0.05 ; \star \star P<0.01$. 
Table 6. Regression results: Organizational drivers of technology- and human-intensiveness.

\begin{tabular}{lcc}
\hline & \multicolumn{2}{c}{$\begin{array}{c}\text { Standardized beta estimates obtained } \\
\text { for two dependent variables }\end{array}$} \\
\cline { 2 - 3 } & \multicolumn{1}{c}{ Technology-intensiveness } & Human-intensiveness \\
\hline Predictor variables: & & \\
Technological opportunism & $0.24 \star \star$ & 0.02 \\
Intelligence dissemination & 0.10 & 0.16 \\
Hierarchy culture & -0.01 & -0.08 \\
Adhocracy culture & 0.08 & $0.27 \star \star$ \\
& & \\
Control variables: & & 0.07 \\
Hotel size (number of rooms) & 0.03 & 0.03 \\
Number of customer segments served & 0.03 & 0.06 \\
Financial slack & 0.12 & 0.02 \\
General manager's industry experience (years) & -0.10 & 0.02 \\
Dummy for suburban hotels & -0.01 & 0.01 \\
Dummy for resort hotels & -0.10 & \\
& & $3.589 \star \star$ \\
Model statistics: & & 0.18 \\
$F$-value & $3.760 \star \star$ \\
$R^{2}$ & 0.19 & \\
\hline
\end{tabular}

$\star \star P<0.01$ 
Figure 1. Four styles of hotel rate-setting.

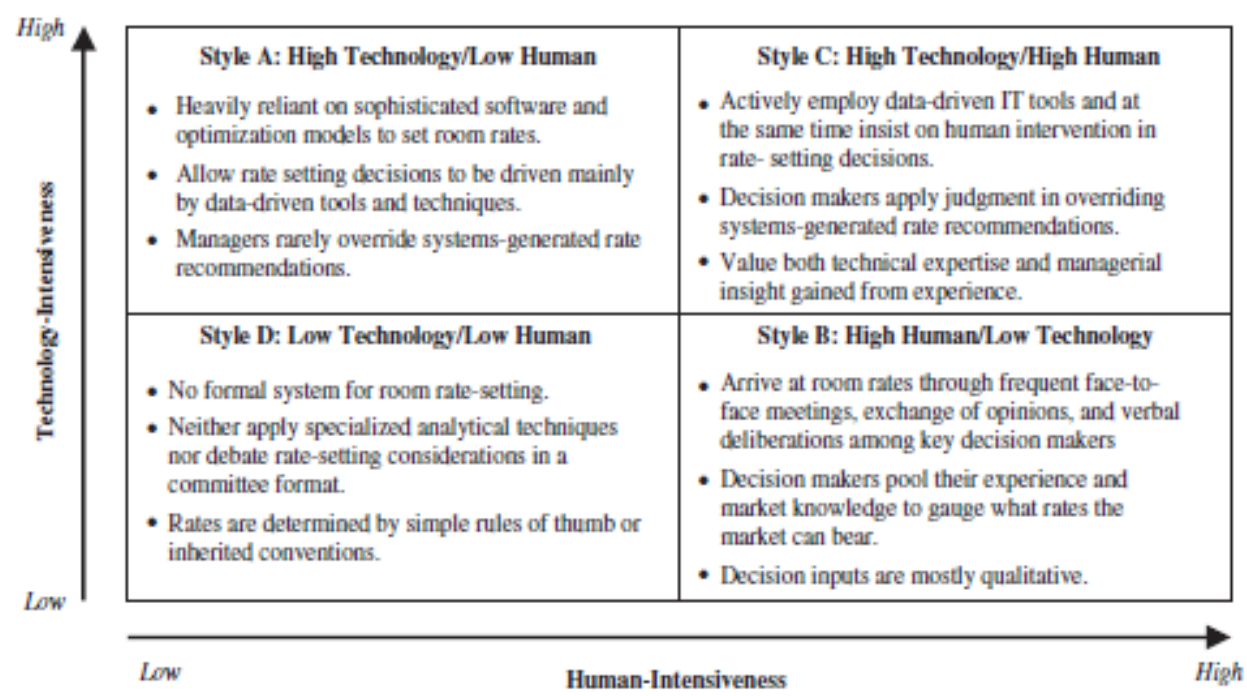


Figure 2. Dendrogram generated from hierarchy clustering procedure.

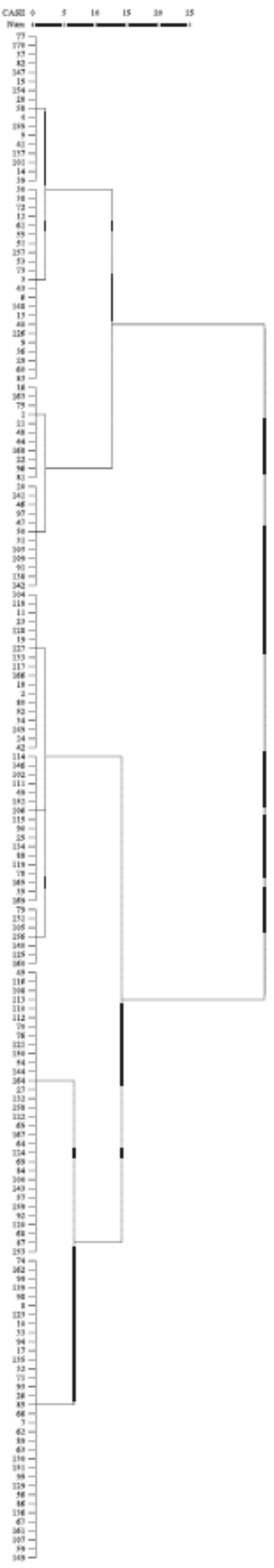


Figure 3. Plot of four final clusters corresponding to four styles of rate-setting.

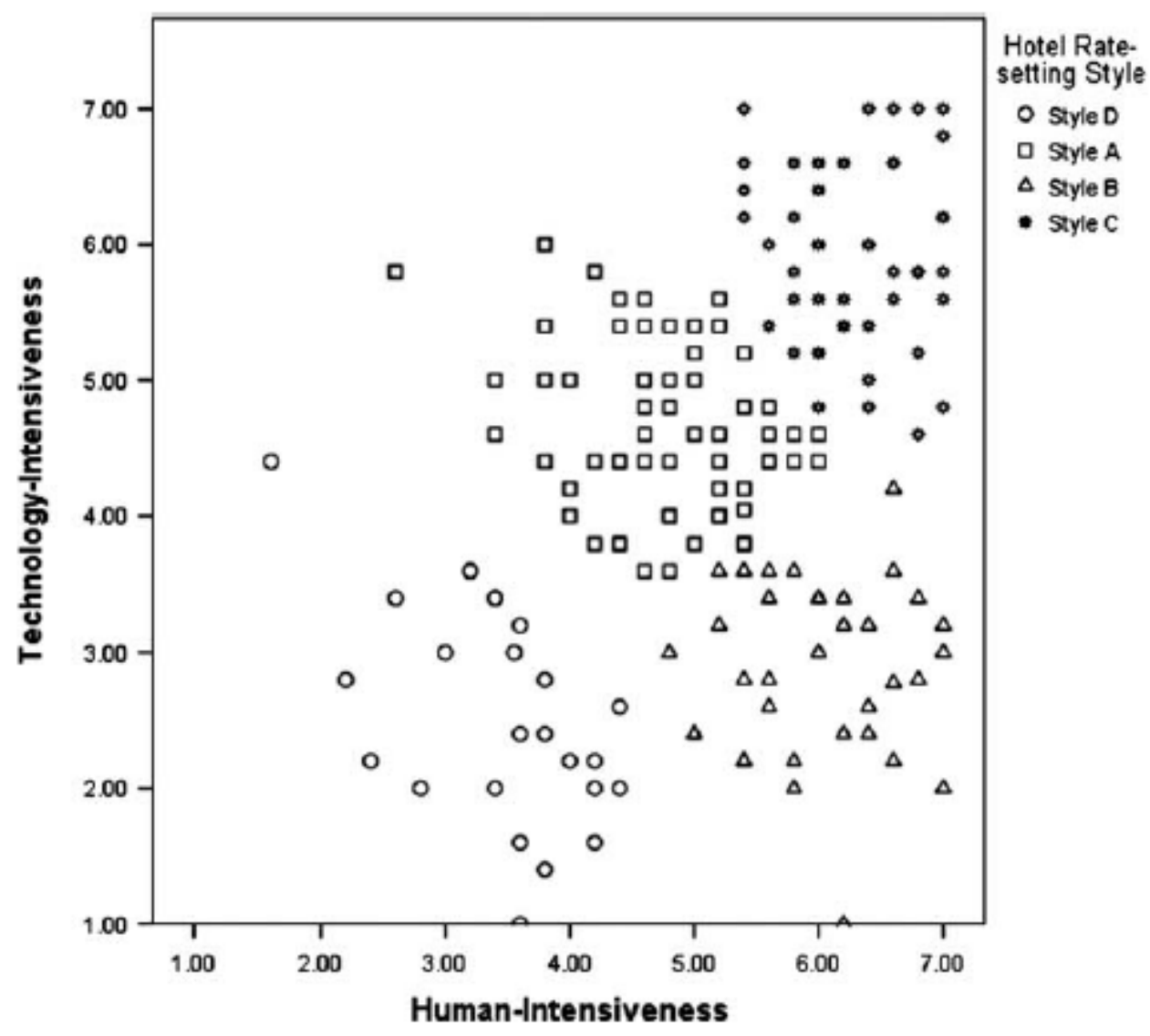


Figure 4. Plot of hotels' degrees of technology- and human-intensiveness by chain.

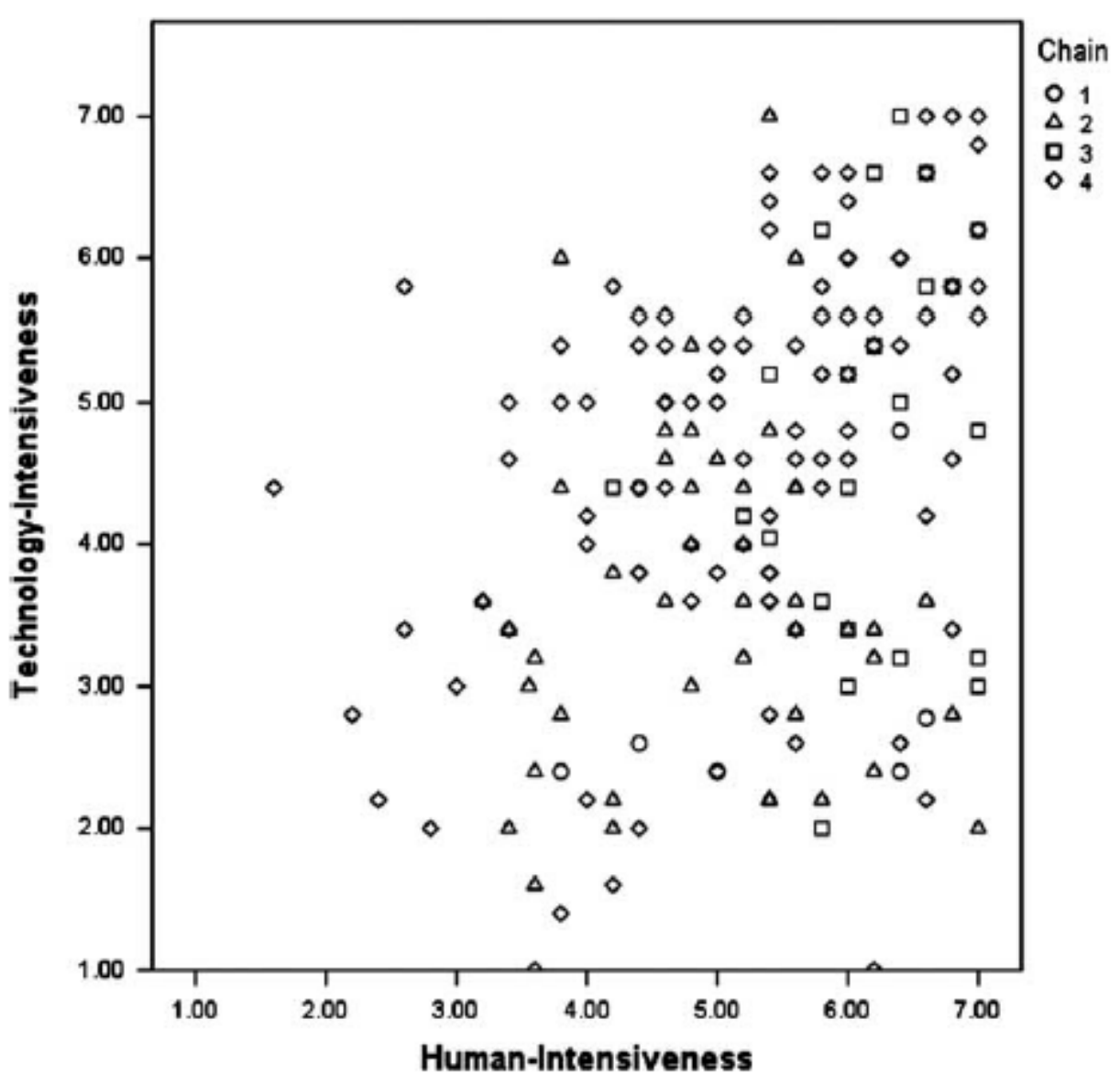


Figure 5. Breakdown of rate-setting styles by financial performance quartiles.

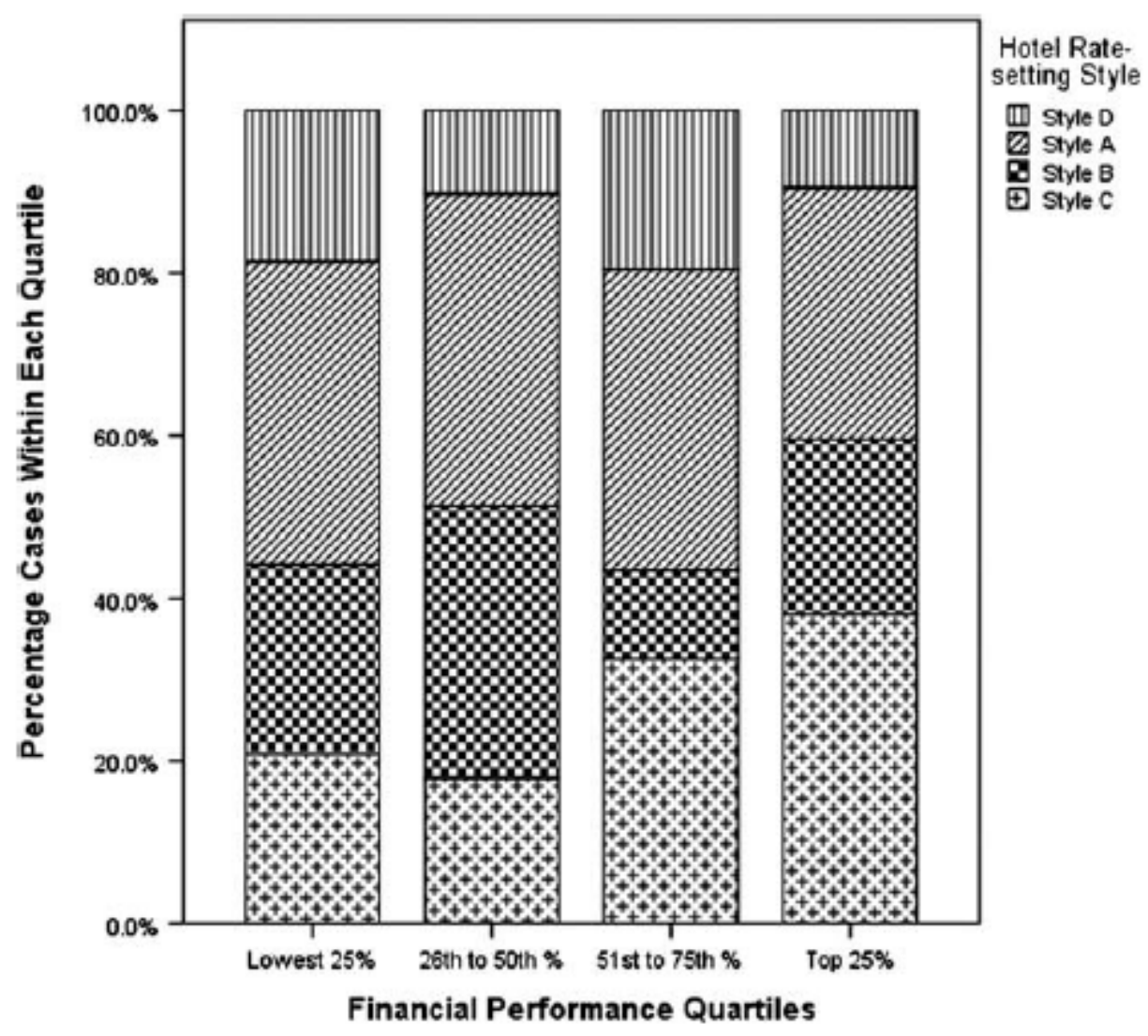




\section{REFERENCES}

Aiken, L.S. and West, S.G. (1991). Multiple Regression: Testing and Interpreting Interactions . Newbury Park, CA: Sage Publications.

Anderson, C.K. and Xie, X. (2010). Improving hospitality industry sales: Twenty-five years of revenue management. Cornell Hospitality Quarterly 51 (1): 53-67.

Choi, S. and Mattila, A.S. (2004). Hotel revenue management and its impact on customers' perceptions of fairness. Journal of Revenue and Pricing Management 2 (4): 303-314.

Churchill Jr, G.A. (1979). A paradigm for developing better measures of marketing constructs. Journal of Marketing Research 16 (1): 64-73.

Cross, R.G., Higbie, J.A. and Cross, D.Q. (2009). Revenue management's renaissance: A rebirth of the art and science of profitable revenue generation. Cornell Hospitality Quarterly 50 (1): 56-81.

Covin, J.G., and Slevin, D.P. (1989). Strategic management of small firms in hostile and benign environments. Strategic Management Journal 10 (1): 75-87.

Cyert, R.M. and March, J.G. (1963). A Behavioral Theory of the Firm . Englewood Cliffs, NJ: PrenticeHall.

Day, G.S. (1994). The capabilities of market-driven organizations. Journal of Marketing 58 (4): 37-52.

Dean, J. (1950). Problems of product-line pricing. Journal of Marketing 14 (4): 518-528.

Deshpande, R., Farley, J.U. and Webster Jr, F.E. (1993). Corporate culture, customer orientation, and innovativeness in Japanese firms: A quadrad analysis. Journal of Marketing 57 (1): 23-37.

Dess, G.G. and Beard, D.W. (1984). Dimensions of organizational task environments. Administrative Science Quarterly 29 (1): 52-73.

Dickson, P.R. (1992). Toward a general theory of competitive rationality. Journal of Marketing 56 (1): 69-83.

Dolan, R.J. and Jeuland, A.P. (1981). Experience curves and dynamic demand models: Implications for optimal pricing strategies. Journal of Marketing 45 (1): 52-62.

Dutta, S., Bergen, M., Levy, D., Ritson, M. and Zbaracki, M. (2002). Pricing as a strategic capability. MIT Sloan Management Review 43 (3): 61-66.

Dutta, S., Zbaracki, M.J. and Bergen, M. (2003). Pricing process as a capability: A resource-based perspective. Strategic Management Journal 24 (7): 615-630.

Enz, C.A., Canina, L. and Lomanno, M. (2009). Competitive pricing decisions in uncertain times. Cornell Hospitality Quarterly 50 (3): 325-341.

Farley, J.U., Hulbert, J.M. and Weinstein, D. (1980). Price setting and volume planning by two European industrial companies: A study and comparison of decision processes. Journal of Marketing 44 (1): 46-54. 
Fornell, C., Johnson, M.D., , Anderson, E.W., , Cha, J. and Bryant, B.E. (1996). The American customer satisfaction index: Nature, purpose, and findings. Journal of Marketing 60 (4): 7-18.

Good, R.E. (1968). Using the computer in pricing. In: E. Marting (ed.). Creative Pricing . New York: American Marketing Association, pp. 182-194.

Hanks, R.D., Cross, R.G. and Noland, R.P. (1992). Discounting in the hotel industry: A new approach. Cornell Hotel and Restaurant Administration Quarterly 33 (1): 15-23.

Houston, M.B., Walker, B.A., Hutt, M.D. and Reingen, P.H. (2001). Cross-unit competition for a market charter: The enduring influence of structure. Journal of Marketing 65 (2): 19-34.

Kaplan, A.D.H., Dirlam, J.B. and Lanzillotti, R.F. (1958). Pricing in Big Business: A Case Approach . Washington DC: The Brookings Institution.

Kerr, N.L. and Tindale, R.S. (2011). Group-based forecasting: A social psychological analysis. International Journal of Forecasting 27 (1): 14-40.

Ketchen, D.J. and Shook, C.L. (1996). The application of cluster analysis in strategic management research: An analysis and critique. Strategic Management Journal 17 (6): 441-458.

Kimes, S.E. (1989). Yield management: A tool for capacity-constrained service firms. Journal of Operations Management 8 (4): 348-363.

Kimes, S.E. (2003). Revenue management: A retrospective. Cornell Hotel and Restaurant Administration Quarterly 44 (5-6): 131-138.

Kimes, S.E. (2011). The future of hotel revenue management. Journal of Revenue and Pricing Management 10 (1): 62-72.

Kohli, A.K. and Jaworski, B.J. (1990). Market orientation: The construct, research propositions, and managerial implications. Journal of Marketing 54 (2): 1-18.

Lawrence, M., Goodwin, P., O'Conner, M. and Onkal, D. (2006). Judgmental forecasting: A review of progress over the last 25 years. International Journal of Forecasting 22 (3): 493-518.

Majumdar, S.K. (1998). On the utilization of resources: Perspectives from the U.S. telecommunications industry. Strategic Management Journal 19 (9): 809-831.

Marn, M.V., Roegner, E.V. and Zawada, C.C. (2004). The Price Advantage . Hoboken, NJ: John Wiley \& Sons.

Matsuno, K., Mentzer, J.T. and Rentz, J.O. (2000). A refinement and validation of the MARKOR scale. Journal of the Academy of Marketing Science 28 (4): 527-539.

Milgrom, P. and Roberts, J. (1990). The economics of modern manufacturing: Technology, strategy, and organization. American Economic Review 80 (3): 511-528.

Miller, D. (1987). The structural and environmental correlates of business strategy. Strategic Management Journal 8 (1): 55-76. 
Miller, D. and Friesen, P.H. (1982). Innovation in conservative and entrepreneurial firms: Two models of strategic momentum. Strategic Management Journal 3 (1): 1-25.

Milligan, G.W. (1980). An examination of the effect of six types of error perturbation on fifteen clustering algorithms. Psychometrika 45 (3): 325-342.

Monroe, K.B. (2003). Pricing: Making Profitable Decisions , 3rd edn. New York: McGraw-Hill.

Morgenroth, W.M. (1964). A method for understanding price determinants. Journal of Marketing Research 1 (3): 17-26.

Nelson, R.R. and Winter, S.G. (1982). An Evolutionary Theory of Economic Change . Cambridge, MA: Belknap Press of Harvard University Press.

Nunnally, J.C. (1978). Psychometric Theory, 2nd edn. New York: McGraw-Hill.

Oxenfeldt, A.R. (1960). Multi-stage approach to pricing. Harvard Business Review 38 (4): 125-133.

Oxenfeldt, A.R. (1973). A decision-making structure for price decisions. Journal of Marketing 37 (1): 4853.

Prasad, K. and Dev, C.S. (2000). Managing hotel brand equity: A customer-centric framework for assessing performance. Cornell Hotel and Restaurant Administration Quarterly 41 (3): 22-31.

Punj, G. and Stewart, D.W. (1983). Cluster analysis in marketing research: Review and suggestions for application. Journal of Marketing Research 20 (2): 134-148.

Quain, W.J., Sansbury, M. and Quinn, D. (1999). Revenue enhancement, part 3: Picking low-hanging fruit - A simple approach to yield management. Cornell Hotel and Restaurant Administration Quarterly 40 (2): 76-83.

Rao, V.R. (ed.). (2009). Handbook of Pricing Research in Marketing . Northampton, MA: Edward Edgar Publishing.

Sampson, R.T. (1964). Sense and sensitivity in pricing. Harvard Business Review 42 (6): 99-105.

Siggelkow, N. (2002). Misperceiving interactions among complements and substitutes: Organizational consequences. Management Science 48 (7): 900-916.

Sodhi, M.S. and Sodhi, N.S. (2011). Six Sigma Pricing: Improving Pricing Operations to Improve Profits . Upper Saddle River, NJ: FT Press.

Srinivasan, R., Lilien, G.L. and Rangaswamy, A. (2002). Technological opportunism and radical technology adoption: An application to e-business. Journal of Marketing 66 (3): 47-60.

Steed, E. and Gu, Z. (2005). An examination of hotel room pricing methods: Practiced and proposed. Journal of Revenue and Pricing Management 3 (4): 369-379.

Tan, J. and Peng, M.W. (2003). Organizational slack and firm performance during economic transitions: Two studies from an emerging economy. Strategic Management Journal 24 (13): 1249-1263. 
Taylor, W. and Kimes, S.E. (2011). The effect of brand class on perceived fairness of revenue management. Journal of Revenue and Pricing Management 10 (3): 271-284.

Thompson, G.L. and Teng, J.T. (1984). Optimal pricing and advertising policies for new product oligopoly models. Marketing Science 3 (2): 148-168.

Vorhies, D.W. and Morgan, N.A. (2005). Benchmarking marketing capabilities for sustainable competitive advantage. Journal of Marketing 69 (1): 80-94.

Weatherford, L.R., Kimes, S.E. and Scott, D.A. (2001). Forecasting for hotel revenue management: Testing aggregation against disaggregation. Cornell Hotel and Restaurant Administration Quarterly 42 (4): 53-64.

Wright, G. and Rowe, G. (2011). Group-based judgmental forecasting: An integration of extant knowledge and the development of priorities for a new research agenda. International Journal of Forecasting 27 (1): 1-13. 